\title{
Organizational Culture, Transformational Leadership and Working Motivation in Moulding Performance of School Supervisors
}

\author{
Sofyan, Soewarto Hardhienata, Rita Retnowati \\ Post Graduate Program, Universitas Pakuan Bogor, Indonesia
}

\begin{abstract}
This study aims at examining the effect of organizational culture, transformational leadership and working motivation to the performance of school supervisors when tested both individually and simultaneously. Variables of organizational culture, transformational leadership and working motivation are treated as independent variables that mold the level of performance of school supervisors as a dependent variable. The research was conducted on proportional randomly selected 231 school supervisors in Jambi Province, Indonesia. Using mix method, a sequential explanatory design is applied where quantitative come first. The study both quantitatively and qualitatively reveals that there is a positive significant relationship among variables under the following distribution of coefficient of correlation: organizational culture to performance of school supervisors $=0.4123$, transformational leadership to performance of school supervisors $=0.4364$, working motivation to performance of school supervisors $=0.3842$, and when tested together it produces coefficient of determination $=0.2340$ indicating the existence of other $76.6 \%$ variables not including in the model affecting performance of school supervisors
\end{abstract}

Keywords: Organizational Culture, Transformational Leadership, Working Motivation, Performance, School Supervisors

\section{INTRODUCTION}

School supervisors are one of the components of educational development that is involved in promoting educational progress as school supervisors are individuals who directly function as drivers of the proper implementation of government policy in the field of education (national standard of education) in every district/city and educational unit. As a guideline for local governments to recruit professional school supervisors, the government has established a school supervisor standard embodied in the Minister of National Education's decree school supervisory standards. There are six dimensions of school supervisor competence, namely: personality competence, managerial supervision competence, academic supervision competence, education evaluation competence, development research competence, and social competence.

The importance of school supervisor's performance towards the achievement of educational objectives is to produce graduates of good quality, both in terms of scientific and personality aspects. If the performance of school supervisors is not good then consequently the learning process conducted by educators is not good as well, and also resulted in the students get less good learning experience affecting the quality of graduates. If this happens, the goal of education is not achieved.

The real condition in the research location based on a preliminary survey on the implementation of the task of school supervisors in 30 supervisors in the Jambi Province indicated the performance of school supervisors was still not as expected. The results of the preliminary survey revealed:

1. $60.00 \%$ of the total school supervisors indicated problematic indication on the quality of the work.

2. $66.67 \%$ of school supervisor indicated the problem on customer satisfaction.

3. $96.67 \%$ of school supervisors indicated problematic indication on the quantity of work result.

4. $56.67 \%$ of the total school supervisors indicated a problem on the indicator of responsibility

5. $66.67 \%$ of the total school supervisors indicate a problematic indication of time utilization indicators.

6. $66.67 \%$ of the school supervisors indicated a problem on the initiative indicator. 
Based on the preliminary survey data above, it can be concluded that the condition of performance of school supervisor is still low and needs to be improved. However, such improvements require considerable time as they relate to the various factors that contribute to it. These factors may include organizational culture, transformational leadership, working motivation and so on.

Based on the background and restriction issues to be examined in this study, it is formulated main points as follows:

1. Is there any relationship between organizational culture and performance of school supervisors?

2. Is there any relationship between transformational leadership and performance of school supervisors?

3. Is there any relationship between working motivation and performance of school supervisors?

4. Are there any simultaneous relationship among organizational culture, transformational leadership and working motivation to performance of school supervisors?

\section{LiterATURE REVIEW}

According to Robinson, et.al (2009), the performance of an individual is the contribution to the achievement of organizational goals. A person's performance will be crucial for the performance of the organization as according to Gibson, et.al (2012) individual performance is the basis for organizational performance. Furthermore, they described that performance is closely related to the behavior of an individual and is influenced by various factors such as (a) the individual variables, consisting of abilities and skills, the background of a person's life including family, experience, and social class; (b) psychological variables, consisting of: motivation, attitude, Interpersonal Communication, perception and learning; (c) organizational variables, consisting of: leadership, organizational resources, organizational structure, and so on.

According to Griffin (2008), performance is determined by three main issues: capabilities, needs, and an environment. Without knowing these three factors, a good performance will not be achieved. It is understandable that people who have a good performance, will know how to do the job properly, have a high desire to do it, and to know the whole main factors that affect their work. Since the behavior of individuals is determined by the combined efforts of the working people and the environment, each individual can make a decision on his behavior in the organization, so that every individual has differences in terms of needs, desires, and goals

Based on the above description, it can be concluded that teacher performance is the contribution of teachers to the achievement of organizational goals that can be seen in the behavior through the performance of teachers in carrying out the tasks assigned to them. The result will be reflected in the output, both the quantity and quality which is characterized by indicators: (a) the planning of learning programs; (b) the implementation of learning programs; (c) evaluation of learning; (d) following up the results of the evaluation.

According to Robbins, Judge, and Boyle (2013), organizational culture is a value system that was developed in an organization that distinguishes these organizations and other organizations. Schein (2012) defines organizational culture or the culture of a group as the basic assumptions learned by a group to solve the problems of external adaptation and internal integration which works quite well and valid. Therefore, the organizational culture is taught to new members as the correct way to feel, think, and feel a connection with the problems.

Further, Schein provides some general understanding of the organizational culture as follows: (a) the regularity of the observed approach when interacting with others; (b) the norms that develop within the group; (c) the dominant values supported by the organization; (d) the philosophy that directs the policies of the organization; (e) the rules of the game that should be followed and accepted by members of the organization; (f) the climate in an organization; (g) the specific competencies of the group shown in completing bounded; (h) the habit of thinking, mental models, and patterns of the language used by members of the group; (i) the emergence of mutual understanding built among group members; and (j) the ideas, feelings, and impressions of the group that built characteristics of themselves as a group.

Bass and Riggio (2006) defines transformational leadership as behavior which can stimulate and inspire followers to achieve results in the process of developing leadership skills, vision and goals 
given organization, to challenge itself to innovate, solve problems, and develop the ability of the leadership to subordinates through guiding, mentoring, challenging and supporting. "Transformational leaders, on the other hand, are then those who stimulate and inspire followers both in achieving extraordinary outcomes and developing their own leadership capacity".

Yukl (2008) stated that transformational leadership is the behavior of a leader who is able to call on his follower's moral values in their efforts to raise awareness of ethical issues and mobilize energy and resources to reform institutions. Factors associated with the above definition are: 1) communicating the vision, 2) expressive, 3) a risk taker and sacrificed himself, 4) communicating high expectations, 5) consistent behavior vision, 6) managing the respect of subordinates against leadership, 7) establishing the existence of a group or organization, 8) empowering subordinates.

Based on the theories mentioned above, it can be synthesized that transformational leadership is the behavior of a leader who can inspire subordinates (teachers) to commit to the vision of the school, communicating, motivating, directing, empowering subordinates, to be a model, developing the potential of subordinates as well as a new perspective in solving the problem. The dimensions and indicators are: 1) the influence of the ideal toward subordinates, 2) the inspiration that motivates, 3) intellectual stimulation, 4) treatment of subordinates, 5) communication skills, 6) the giver of challenge and support.

Gibson, et. al (2012) stated that the motivation is characterized with (a) direct from behavior, (b) the strength of the response once an employee chooses to follow the action, and (c) persistence behavior. Furthermore, Colquitt, Lepine, and Wesson (2009) define motivation as a set of energy forces originating both inside and outside employees, determine the direction, intensity, and persistence. Various theories emphasized that there are three elements of motivation, (a) attempts; (B) the organization's goals; $(\mathrm{C})$ requirement. This element is a measure of the intensity of the effort, in this case, if a person is motivated to do his job he will not bend over backward so that high effort will produce outcomes. Thus, work motivation means a push of a person's desire to carry out actions or activities within the scope of the tasks of the job/position within an organization.

From the above description, it can be concluded that, work motivation is the force that drives, moves, and directs both from within and from outside the individual to carry out work in order to achieve the stated goals of both individuals and organizations, which is characterized by the indicators of (a) responsibilities; (b) self-development; (c) independence; (d) the relationship among members; (e) wages earned; (f) the attention of the employer; and (g) meeting the needs of the workplace.

Based on the above it can be concluded that organizational culture is a way of viewing and basic assumptions underlying values, norms, and beliefs of individuals within the organization and are formed from the interaction between members of the organization to achieve common goals. The indicators: (a) complying with the norms; (b) the values that are believed; (c) trust in the organization; (d) coherence with other members of the organization; (e) a clear roadmap; and (f) the seriousness to the achievement of working together in the organization.

Based on the study of the theory described above, the following hypothesis is formulated:

1. There is a positive relationship between organizational culture and performance of school supervisors.

2. There is a positive relationship between transformational leadership and performance of school supervisors.

3. There is a positive relationship between working motivation, and performance of school supervisors.

4. There is a positive relationship between organizational culture, transformational leadership, and working motivation simultaneously with the performance of school supervisors.

\section{Methodology}

This study applies Sequential Explanatory Design Mixed Method where the quantitative study is ahead of the qualitative study to examine the relationship between variables tested in the study using three independent variables through data obtained from questionnaires. The independent variable is organizational culture $\left(\mathrm{X}_{1}\right)$, transformational leadership $\left(\mathrm{X}_{2}\right)$, and working motivation $\left(\mathrm{X}_{3}\right)$, while the dependent variable is the performance of school supervisors $(\mathrm{Y})$. 
The relationship among variables in the study described in Fig.1 below:

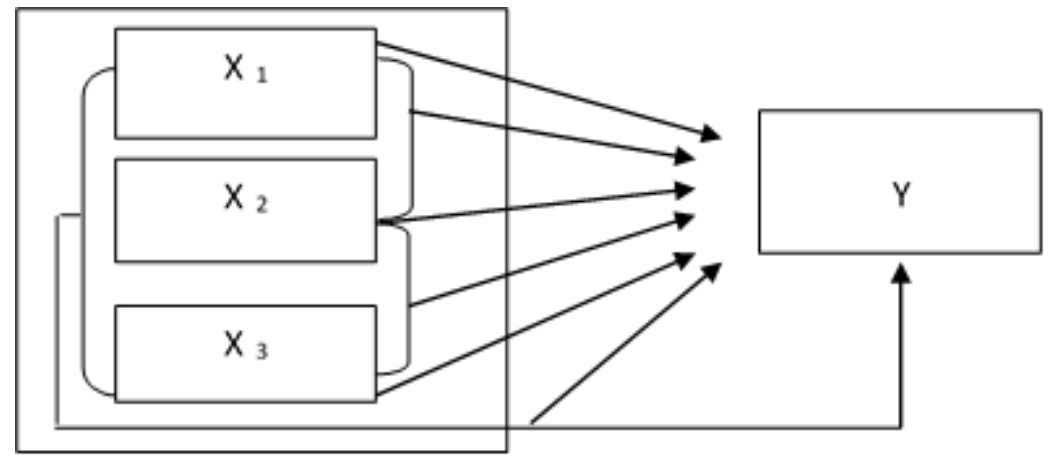

Figure1. Theoretical framework

Where,

$\mathrm{Y}=$ Performance of School Supervisors

$\mathrm{X}_{1}=$ Organizational Culture

$\mathrm{X}_{2}=$ Transformational Leadership

$\mathrm{X}_{3}=$ Working Motivation

The sampling technique is purposive random sampling as many as 231 school supervisors. Hypothesis testing is conducted by using regression analysis to determine the influence of one or more independent variables on the dependent variable. Hypothesis testing is performed at a signifycance level of 0.05 .

Qualitative study for the purpose of confirmation was performed through observation and interview to key informants of 11 selected school supervisors from 11 regencies in Jambi Province.

\section{RESUlt AND DISCUSSION}

The teachers of listed organizations were asked to participate in the survey by responding their opinions for four different measures in organizational culture, transformational leadership, working motivation and performance of school supervisors. The normality is performed with Lilliefors test. Data are normally distributed as the value of each variable is not exceeding the critical value for Lilliefors test. The Lilliefors normality test values for organizational culture, transformational leadership, working motivation are $0.0412,0.0476$ and 0.0386 respectively below the critical value of 0.583 for $\mathrm{n}=231$.

\subsection{Organizational Cultures and Performance of School Supervisors}

The strength of the relationship between organizational culture and school supervisor's performance is shown by the correlation coefficient $=0.4123$. The calculation results obtained t-test $=6.88$ while $\mathrm{t}$ table $(\alpha=0.05)=1.970$. Since the value of $\mathrm{t}$-test is $>$ than the value of $\mathrm{t}$-table, it is concluded that the correlation coefficient between organizational culture and school supervisors' performance is significant.

The coefficient of determination between organizational culture and school supervisor performance is $r=0.170$. This means that $17 \%$ performance of school supervisors is the result of contributions from organizational culture.

The hypothesis that there is a positive influence of organizational culture on school supervisor performance is accepted meaning that organizational culture improvement will also lead to an increase in the performance of school supervisors. This positive influence is also supported by the results of qualitative research based on the results of interview analysis, Focus Group Discussion (FGD), observation and documentation on 11 (eleven) districts / municipalities in Jambi Province proving that there is a tendency of relationship between organizational culture with school supervisor performance that strengthens the results of quantitative research.

This is in accordance with the theory put forward by Colquit et. al, that the organizational culture is shared social knowledge within an organization about the rules, norms, and values that shape the attitudes and behaviors of employees. Similarly, according to Robbin that the culture of the 
organization tends to be interpreted by members of the organization as a system adopted, which differentiates an organization with other organizations.

The results of previous relevant studies also proved that organizational culture has a positive influence on performance, one of which is Mujeeb et.al, (2011) which shows that there is a positive relationship between organizational culture and performance.

Based on the above description it is concluded that the higher the organizational culture, the higher the performance of school supervisors. Thus the findings of facts and data in the analysis of this study further support the previous findings on the positive relationship between the organizational culture with the performance of school supervisors.

\subsection{Transformational Leadership and Performance of School Supervisors}

The strength of the relationship between transformational leadership and school supervisor's performance is shown by the correlation coefficient $=0.4364$. The calculation results obtained t-test $=$ 7.37 while t-table $(\alpha=0.05)=1.970$. Since the value of t-test is $>$ than the value of t-table, it is concluded that the correlation coefficient between transformational leadership and school supervisors' performance is significant.

The coefficient of determination between transformational leadership and school supervisor performance is $r=0.190$. This means that $19 \%$ performance of school supervisors is the result of contributions from transformational leadership.

The hypothesis that there is a positive influence of transformational leadership on school supervisor performance is accepted meaning that transformational leadership improvement will also lead to an increase in the performance of school supervisors. This positive influence is also supported by the results of qualitative research based on the results of interview analysis, Focus Group Discussion (FGD), observation and documentation on 11 (eleven) districts / municipalities in Jambi Province proving that there is a tendency of relationship between transformational leadership with school supervisor performance that strengthens the results of quantitative research.

This is reinforced by the theory put forward by Robbins \& Judge that transformational leadership is a leadership that inspires followers to set aside personal interests for the good of the organization and has a tremendous influence on followers. The transformational leadership factors that can influence the followers are a. providing vision and mission and instill pride, b.communicating high expectations and delivering important goals simply; c. increasing rationality and improving intelligence, $d$. giving special attention to the individual and treating followers individually.

Previously relevant studies have proved that transformational leadership has a positive effect on performance, one of which is the study of Cavazotte et al (2013) which concludes that the relationship between transformational leadership has a significant direct effect on performance.

Thus the findings of facts and data in the analysis of this study further support the earlier findings of the positive influence of transformational leadership with performance.

\subsection{Work Motivation and Performance of School Supervisors}

The strength of the relationship between work motivation and school supervisor's performance is shown by the correlation coefficient $=0.3842$. The calculation results obtained t-test $=6.33$ while $\mathrm{t}$ table $(\alpha=0.05)=1.970$. Since the value of $t$-test is $>$ than the value of $t$-table, it is concluded that the correlation coefficient between work motivation and school supervisors' performance is significant.

The coefficient of determination between work motivation and school supervisor performance is $r=$ 0.148 . This means that $14.8 \%$ performance of school supervisors is the result of contributions from work motivation.

The hypothesis that there is a positive influence of work motivation to school supervisor performance is accepted meaning that work motivation improvement will also lead to an increase in the performance of school supervisors. This positive influence is also supported by the results of qualitative research based on the results of interview analysis, Focus Group Discussion (FGD), observation and documentation on 11 (eleven) districts / municipalities in Jambi Province proving that there is a tendency of relationship between work motivation with school supervisor performance that strengthens the results of quantitative research. 
The theory proposed by Colquitt, et. al, that motivation is a collection of energetic forces that coordinate within and outside a worker, which encourages effort, work, in determining direction, intensity, and persistence, with elements or dimensions: a. initiatives, b. determined direction, c. intensity, and d. perseverance.

Relevant previous research results have also proved that work motivation has a positive influence on performance, one of which is the study of Susan et.al (2012) showed that work motivation has a positive and significant impact on performance.

Thus the findings of facts and data in the analysis of this study further support the previous findings regarding the positive influence of work motivation with the performance of school supervisors.

\subsection{Organizational Culture, Transformational Leadership, and Work Motivation to Performance of School Supervisors}

The result of hypothesis testing shows that the functional relationship between $X_{1}, X_{2}$, and $X_{3}$ with $Y$ is presented in the form of multiple regression equations: $Y=63.068+0.50 \mathrm{X}_{1}+0.276 \mathrm{X}_{2}+0.271$ $\mathrm{X}_{3}$. Since the value of calculated-F (23.189) is $>\mathrm{F}_{\text {tabel }}(\alpha=0.05)=2.644$, it can be concluded that the relationship between organizational culture $\left(\mathrm{X}_{1}\right)$, transformational leadership $\left(\mathrm{X}_{2}\right)$ and work motivation $\left(\mathrm{X}_{3}\right)$ together with the performance of school supervisors is positive and significant. The coefficient of determination is 0.2340 meaning that $23.40 \%$ variation of performance of school supervisors can be explained by variables of organizational culture $\left(\mathrm{X}_{1}\right)$, transformational leadership $\left(\mathrm{X}_{2}\right)$ and work motivation $\left(\mathrm{X}_{3}\right)$ simultaneously while $76.60 \%$ are determined by other variables that do not include in the model.

The above result is reinforced by the results of qualitative research on the focus of qualitative research with the result that organizational culture, transformational leadership and work motivation on school supervisor performance show the tendency similar to the results of quantitative research. Another contributing factor of $76.60 \%$ was revealed through the focus of qualitative research. The findings of other factors that allegedly contributed to the achievement of school supervisor performance are: 1) ability, 2) team communication, 3) feedback, 4) task complexity, 6) team characteristics, 7) challenge, 8) trust Justice \& ethics, 9) leadership style, 10) persistence, 11) learning \& decision making, 12) awards, 13) demography, 14) personality \& cultural values, 15) work stress, and 16) work climate.

\section{Conclusion}

There is a positive relationship between organizational culture to the performance of school supervisors with the coefficient of correlation $=0.4123$ and coefficient of determination $=0.170$ $(17 \%)$. This positive relationship is reinforced by qualitative research results leading to the conclusion that the higher the organizational culture the higher the performance of school supervisors.

There is a positive relationship between transformational leadership to performance of school supervisors with the coefficient of correlation $=0.4364$ and coefficient of determination $=0.190$ (19\%). This positive relationship is reinforced by qualitative research results leading to the conclusion that the higher the transformational leadership the higher the performance of school supervisors.

There is a positive relationship between work motivation to performance of school supervisors with the coefficient of correlation $=0.3842$ and coefficient of determination $=0.1480(14.8 \%)$. This positive relationship is reinforced by qualitative research results leading to the conclusion that the higher the work motivation the higher the performance of school supervisors.

There is a positive relationship of organizational culture, transformational leadership, and work motivation altogether with the performance of school supervisors shown by regression equation $\hat{Y}=$ $63.068+0.050 \mathrm{X}_{1}+0.276 \mathrm{X}_{2}+0.271 \mathrm{X}_{3}$ with coefficient of correlation $=0.638$ and coefficient of determination $=0.2340(23.40 \%)$. This relationship is reinforced by qualitative research results leading to the conclusion that the higher the organizational culture, transformational leadership, and work motivation altogether the higher the performance of school supervisors.

\section{REFERENCES}

[1] Bass, B. M., \& Riggio, R. E. (2006). Transformational leadership. Psychology Press.

[2] Cavazotte, F., Moreno, V., \& Bernardo, J. (2013). Transformational leaders and work performance: the mediating roles of identification and self-efficacy. BAR-Brazilian Administration Review, 10(4), 490-512. 
[3] Colquitt, J., Lepine, J. A., \& Wesson, M. J., Organizational Behavior: Improving performance and commitment in the workplace. McGraw-Hill/Irwin, 2009, ch.2 pp. 66-70

[4] Gibson, J. L., Ivancevich, J. M., \& Donnelly, J. H. Konopaske, Organizations: Behavior, Structure, processes, 14 (2012).

[5] Griffin, R. W. (2008). Principles of management. Recording for the Blind \& Dyslexic.

[6] Mujeeb, E. M., Masood, M. M., \& Ahmad, M. A. (2011). The relationship between organizational culture and performance management practices: a case of university in Pakistan. Journal of Competitiveness, 3(4).

[7] Robbins, S., Judge, T. A., Millett, B., \& Boyle, M. (2013). Organizational behavior. Pearson Higher Education AU.

[8] Robinson, L., Brittain, K., Lindsay, S., Jackson, D., \& Olivier, P. (2009). Keeping in Touch Everyday (KITE) project: developing assistive technologies with people with dementia and their carers to promote independence. International Psychogeriatrics, 21(03), 494-502.

[9] Susan, W. M., Gakure, R. W., Kiraithe, E. K., \& Waititu, A. G. (2012). Influence of Motivation on Performance in the Public Security Sector with a Focus to the Police Force in Nairobi, Kenya. International Journal of Business and Social Science, 3(23).

[10] Schein, E. (2012). Corporate culture. Handbook for Strategic HR: Best Practices in Organization Development from the OD Network, 253.

[11] Yukl, G. (2008). How leaders influence organizational effectiveness. The leadership quarterly, b19 (6), 708-722. 